\title{
Formulation and evaluation of Bacillus coagulans- loaded hypromellose mucoadhesive microspheres
}

This article was published in the following Dove Press journal:

International Journal of Nanomedicine

29 March 2011

Number of times this article has been viewed

\section{Sk Md Athar Alli \\ Department of Pharmaceutical Technology, Jadavpur University, Kolkata, West Bengal, India}

Correspondence: Sk Md Athar Alli Department of Pharmacy, VBS Purvanchal University, Jaunpur-222 00I, Uttar Pradesh, India $\mathrm{Tel} / \mathrm{fax}+915452252567$

Mobile +9| 93 366| 3422

Email smatharalli@gmail.com
Abstract: Development of a novel delivery system has been attempted to deliver viable probiotic cells into the gut for a prolonged period of time while maintaining high numbers of viable cells within the formulation throughout the shelf-life of the product and during the gastrointestinal transit. Core mucoadhesive microspheres of Bacillus coagulans were developed employing several grades of hypromellose, a mucoadhesive polymer, following coacervation and phase separation technique and were subsequently enteric-coated with hypromellose phthalate. Microspheres were evaluated for percent yield; entrapment efficiency; in vitro swelling; surface morphology; particle size, size distribution, and zeta potential; flow property, mucoadhesion property by the ex vivo mucoadhesive strength test and the in vitro wash off test; in vitro release profile and release kinetic; in vivo probiotic activity; and stability. The values for the kinetic constant and regression coefficient of model-dependent approaches and the difference factor $\left(f_{1}\right)$, the similarity factor $\left(f_{2}\right)$, and the Rescigno index $\left(\xi_{1}\right.$ and $\left.\xi_{2}\right)$ of model independent approaches were determined for comparing in vitro dissolution profiles. Freeze dried B. coagulans cells were successfully formulated as enteric-coated mucoadhesive microspheres with satisfactory physical structure and yield. The viability of $B$. coagulans was maintained in the simulated gastric conditions and during processing; in simulated intestinal conditions exhibiting mucoadhesion, and controlling and extending the viable cell release following zero-order; and was satisfactorily stable at room temperature. Test results depict statistically significant effects of the hypromellose grade and their concentration on the performance and release profile of formulations.

Keywords: probiotics, B. coagulans, mucoadhesive, microspheres, extended-release

\section{Introduction}

Reported health benefits of probiotics such as suppressing the growth of undesirable microorganisms in the colon and in the small intestine, controlling serum cholesterol level, reducing the risk of colon cancer, stimulating the immune system, improving lactose utilization, and controlling the allergic inflammation associated with food allergy has created a large market of probiotic foods worldwide. ${ }^{1-7}$ The therapeutic benefit of probiotics is associated with its ability to secrete a bacteriocin, coagulin, which is active against a broad spectrum of enteric microbes. ${ }^{7}$ To be therapeutically active, probiotics must arrive in the intestine alive and in sufficient numbers which is suggested at $10^{6}-10^{7}$ colony-forming units (cfu). ${ }^{8}$ B. coagulans, commonly mislabeled as Lactobacillus sporogenes, also suffers with wide variation between the actual content and the labeled claim of viable spores, as in other probiotic strains. ${ }^{7,9}$ Reduction in cell viability within the dosage form results from the freeze-drying operation of probiotics during the initial manufacturing, the processing conditions during formulation, and noncompliance to 
storage requirements during transportation and storage. ${ }^{7-12}$ After their consumption, the hydrolytic enzymes, the acidic conditions of stomach, and the bile salts in the gastrointestinal (GI) tract also adversely affect the viability of probiotics..$^{7,12-15}$ Various approaches such as the addition of different growth promoters, manipulation of fermentation and storage conditions of the food carriers, careful selection of the culture organisms according to their interrelationships and acid-bile resistance, and employing microencapsulation technology have been investigated to improve the amount of viable cells arriving in the intestine. ${ }^{7,13-15}$ However, all of these approaches have varying degrees of success, as maintenance of high numbers of viable cells within the product throughout its shelf-life and during GI transit is a challenge. Amongst all the above approaches, microencapsulation technologies have attracted considerable attention but their short residence time at the site of action/absorption limits their performance. Coupling mucoadhesion characteristics to microspheres through developing mucoadhesive microspheres in turn will enhance their residence time and specifically can target $\operatorname{drug}(\mathrm{s})$ to the site of action/absorption and thereby enhance performance. ${ }^{16,17}$ Hypromellose has been used as a polymer in the preparation of mucoadhesive microspheres due to its favorable mucoadhesive properties, and is safe for human oral consumption. ${ }^{16-18}$ Hypromellose and hypromellose phthalate are compatible with B. coagulans ${ }^{19}$ and possess aqueous solubility. ${ }^{20}$

In the context of the above principles, there is a need to develop a dosage form that will deliver B. coagulans into the gut for a prolonged period of time with adequate stability during storage and GI transit. Thus, the present investigation attempted to prepare $B$. coagulans loaded mucoadhesive microspheres, using several grades of hypromellose and subsequently enteric-coated with hypromellose phthalate, in order to deliver viable $B$. coagulans into the gut for an extended period of time protecting against the harsh conditions of the GI tract and having an adequate shelf-life.

\section{Materials and methods}

\section{Materials}

Freeze dried B. coagulans (powder) and hypromellose phthalate (HP-50) were gift samples from Glenmark Pharmaceuticals Limited (Sinnar, Nasik, India). Grades of hypromellose (hydroxypropylmethylcellulose or HPMC) namely Methocel E5 Premium LV, Methocel E15 Premium LV, and Methocel K15M Premium were received from Indoco Remedies Limited (Rabale, Mumbai, India). Glucose Yeast Extract (GYE), agar media, and other analytical grade laboratory chemicals were purchased from HiMedia Laboratories Pvt Limited (Mumbai, India).

\section{Methods}

\section{In-house compliance test of $B$. coagulans}

Identification tests (description, microscopic examination, qualitative test for lactic acid production), viable B. coagulans spore count, estimation of the lactic acid-producing capacity, determination of loss on drying, and ensuring the absence of contaminants were done as per the method of analysis provided by the manufacturer.

\section{Preparation of mucoadhesive microspheres}

Core B. coagulans loaded mucoadhesive microspheres were prepared with hypromellose, employing coacervation and phase separation technique. ${ }^{16,17}$ Briefly, hypromellose $(2.5 \mathrm{~g})$ was dissolved in $100 \mathrm{~mL}$ of cold de-ionized (DI) water $\left(4 \pm 2^{\circ} \mathrm{C}\right)$. One hundred $\mathrm{mg}$ of tween-80 was dissolved in the above solution with stirring. Resultant solution was filtered aseptically using $0.45 \mu \mathrm{m}$ PVDF filter membrane (Millipore, Bedford, MA). A calculated quantity of $B$. coagulans was dispersed in the above solution, under stirring. The temperature of the resultant dispersion was raised gradually up to $30 \pm 2{ }^{\circ} \mathrm{C}$ with stirring at $500 \pm 25$ revolutions per minute (rpm) for 30 minutes. Acetone $(25 \mathrm{~mL})$ was added drop-wise with stirring at $300 \pm 25 \mathrm{rpm}$ for 10 minutes. Microspheres thus obtained were filtered aseptically with $10 \mu \mathrm{m}$ nylon filter (NY10; Millipore), washed twice with sterile water for injection $\left(30 \pm 2^{\circ} \mathrm{C}\right)$ and then kept in a desiccator for 24 hours. The entire process was carried out aseptically on a bench of horizontal laminar flow clean air work station (1500048-24-24; Klenzaids Bioclean Devices (P) Ltd, Mumbai, India). All formulation batches were prepared in triplicate following the above method to verify reproducibility and their composition is summarized in Table 1.

\section{Coating of microspheres}

One hundred $\mathrm{mL}$ of hypromellose phthalate solution $(10 \%$ $\mathrm{w} / \mathrm{w}$ ) was prepared by dissolving HP-50 in phosphate buffer pH-6.8 $8^{21}$ with stirring. Two g of polyethylene glycol 200 (PEG-200) and $100 \mathrm{mg}$ of tween-80 was added to it with stirring. The above solution was filtered aseptically using a $0.45 \mu \mathrm{m}$ PVDF filter membrane. Core microspheres were dispersed in the above solution with stirring at $300 \pm 25 \mathrm{rpm}$ followed by drop-wise addition of $20 \mathrm{~mL}$ of propan-2-ol. Stirring was continued for 30 minutes. Coated microspheres, thus obtained, were filtered and washed thrice with sterile 
Table I Formulation formula and percent yield value and entrapment efficiency value of all formulation batches

\begin{tabular}{lllll}
\hline $\begin{array}{l}\text { Formulation } \\
\text { code }\end{array}$ & Polymer used & $\begin{array}{l}\text { B. coagulans to } \\
\text { polymer ratio }\end{array}$ & $\begin{array}{l}\text { Percent yield } \\
(\mathbf{w} / \mathbf{w})^{*}\end{array}$ & $\begin{array}{l}\text { Entrapment efficiency } \\
(\% \mathbf{w} / \mathbf{w})^{*}\end{array}$ \\
\hline FI & Methocel E5 & $1: 1$ & $68.1 \pm 3.12$ & $85.36 \pm 2.23$ \\
F2 & Premium LV & $1: 2$ & $66.6 \pm 3.09$ & $78.41 \pm 1.76$ \\
F3 & I:3 & $1: 1$ & $64.4 \pm 3.18$ & $72.22 \pm 1.76$ \\
F4 & Methocel EI5 & $1: 2$ & $65.3 \pm 3.59$ & $78.00 \pm 2.31$ \\
F5 & Premium LV & $1: 3$ & $63.4 \pm 3.67$ & $74.92 \pm 1.91$ \\
F6 & & $1: 1$ & $62.1 \pm 3.24$ & $70.68 \pm 1.79$ \\
F7 & Methocel KI5M & $1: 2$ & $59.4 \pm 3.17$ & $73.56 \pm 2.54$ \\
F8 & Premium & $1: 3$ & $56.2 \pm 3.81$ & $71.74 \pm 2.86$ \\
F9 & & $54.6 \pm 3.46$ & $67.68 \pm 2.31$ \\
\hline
\end{tabular}

Note: $*$ Data are presented as mean value $\pm S E, n=3$.

water for injection $\left(30 \pm 2^{\circ} \mathrm{C}\right)$, kept in a desiccator for 24 hours, transferred aseptically to a sterile glass vial, sealed hermetically, and stored in a refrigerator for further manipulation. The entire process was carried out aseptically on a bench of horizontal laminar flow clean air work station, in triplicate to observe reproducibility of the process.

\section{Percent yield study}

Percent yield (w/w) of microspheres was calculated employing equation-1.

Percent yield $=\frac{\mathrm{W}_{1}(\text { Weight of microsphere recovered })}{\mathrm{W}_{2}(\text { Weight }[\text { drug }+ \text { polymer }])} \times 100$

\section{Calibration curve of $B$. coagulans}

Several standard concentrations of dispersions containing B. coagulans were prepared with the sterile simulated gastric fluid $T S$ and the sterile simulated intestinal fluid $T S$ separately. The respective absorbance optical density (OD) was measured at $600 \mathrm{~nm}$ with respect to their respective blank, employing UV/Vis spectroscopic method (UV-1700; Shimadzu, Kyoto, Japan), so as to get a calibration curve that relates the OD values to cell concentration. ${ }^{22}$ When a standard B. coagulans dispersion was analyzed repeatedly $(n=3)$, the mean error (accuracy) was found to be $0.98 \%$ and relative standard deviation (precision) was found to be $1.5 \%$, indicating validity of the method for linearity, accuracy, and precision. The OD test is the best way to enumerate roughly the total number of cells (viable plus nonviable) present in the sample and helps to determine the dilution factor for performing viable spore count but fails to reveal cfu, the unit for expressing the number of viable cells. The simulated gastric fluid $T S^{21}$ and the simulated intestinal fluid $T S^{21}$ contains inorganic salts but no carbon source, thus $B$. coagulans cells will not proliferate in this media but will remain in a state of stasis until they are plated on media containing a carbon source.

\section{Viable B. coagulans spore count}

The number of viable spores in the sample was determined by employing the following procedure. ${ }^{19}$

\section{Dilution and heat-treatment}

One gram of sample alternating with $1 \mathrm{~mL}$ of sample solution containing $B$. coagulans was transferred aseptically into a pre-sterilized $10 \mathrm{~mL}$ volumetric flask containing $5 \mathrm{~mL}$ of sterile saline $T S$ and mixed thoroughly by sonication for 2 minutes. The volume was made up to $10 \mathrm{~mL}$ with sterile saline $T S$. One $\mathrm{mL}$ of the above suspension was diluted to $10 \mathrm{~mL}$ with sterile saline $T S$ in an autoclaved test tube $(25 \mathrm{~mm}$ by $150 \mathrm{~mm}$ size). This serial dilution method was continued until a suitable dilution was achieved (approximately $100 \mathrm{cell} / \mathrm{mL}$ ). The final dilution tube was allowed to stand in a water bath at $70^{\circ} \mathrm{C}$ for 30 minutes and then cooled immediately to about $45^{\circ} \mathrm{C}$. Saline $T S^{21}$ contains inorganic salts but no carbon source; thus $B$. coagulans will not proliferate in this media but will remain in a state of stasis until they are plated on media containing carbon source.

\section{Plating}

GYE agar medium was liquefied and cooled to $45^{\circ} \mathrm{C}$ in a water bath. One $\mathrm{mL}$ of sample from the heat-treated final dilution tube was transferred into each sterile petri dish (six per sample) followed by pouring $15 \mathrm{~mL}$ of molten medium and mixing and then incubating in an inverted position at $40^{\circ} \mathrm{C}$ for 48 hours after solidification.

\section{Counting}

Six plates were counted and the average count per plate was calculated. The number of cfu per unit (mL or gram) of sample was calculated by employing equation-2. 


$$
\begin{aligned}
& \text { Number of cfu } \\
& =\frac{\text { Average number of colonies counted per plate }}{\text { Dilution factor }}
\end{aligned}
$$

\section{Entrapment efficiency study}

Two hundred mg of accurately weighed microspheres were transferred aseptically into a sterile glass vial containing $10 \mathrm{~mL}$ of sterile simulated intestinal fluid $T S$, sealed hermetically and kept at $4 \pm 2^{\circ} \mathrm{C}$ for 24 hours. The dispersion was subjected to a viable $B$. coagulans spore count and the entrapment efficiency value was calculated using equation-3 and is reported in percent.

Entrapment efficiency $=\frac{\text { Practical spore count }}{\text { Theoretical spore count }} \times 100$

\section{In vitro swelling study}

An in vitro swelling test of microspheres was conducted in simulated intestinal fluid TS. The size of dried microspheres and those after incubation in simulated intestinal fluid for 5 hours were measured using a calibrated optical microscope (CX RIII; Labomed, Ambala, India). Percent swelling value was determined from the diameter of microspheres at time $\mathrm{t}$ $\left(D_{T}\right)$ and initial time $\mathrm{t}=0\left(D_{0}\right)$ using equation-4. ${ }^{23}$

$$
\text { Percent swelling }=\left[D_{T}-D_{0}\right] / D_{0} \times 100
$$

\section{Morphological examination of microspheres}

Coated microspheres were mounted on the aluminum stubs using double-sided adhesive tape. The stubs were then vacuumcoated with a thin layer of gold and examined with a scanning electron microscope (JSM 5610 LV; Jeol, Tokyo, Japan). ${ }^{16}$

\section{Particle size, size distribution, and zeta potential study}

The core and the coated microspheres were dispersed in DI water ( $\mathrm{pH} 6.8$ ) and sonicated for 2 minutes to get a homogenous dispersion $(0.5 \% \mathrm{w} / \mathrm{v})$. The resultant dispersions contained in small volume disposable zeta cells were subjected to particle size study using photon correlation spectroscopy with in-built Zetasizer (Nano ZS; Malvern Instruments, Worcestershire, UK) at $633 \mathrm{~nm}$ and $25 \pm 0.1^{\circ} \mathrm{C}$. Measured electrophoretic mobility $(\mathrm{mm} / \mathrm{s})$ is converted to zeta potential by in-built software based on the Helmholtz-Smoluchowski equation. ${ }^{24}$

\section{Flow property study}

The flow property of coated microspheres was determined from the results of study parameters namely: Angle of repose $(\alpha)$, equation-5; Carr's index (CI), equation-6; and Hausner ratio $(H R)$, equation-7. ${ }^{21}$ Angle of repose was determined by the fixed funnel method and is calculated from the height $(H)$ and the radius $(R)$ of the powder hip. Microspheres were placed in a graduated cylinder and the initial volume before tapping $\left(V_{0}\right)$ was noted then they were tapped with a tap density apparatus (ETD-1020; Electrolab, Mumbai, India) to a constant volume so as to get tapped volume $\left(V_{T}\right)$.

$$
\begin{gathered}
\alpha=\tan ^{-1}[H / R] \\
C I=\left[\left(V_{0}-V_{T}\right) / V_{0}\right] \times 100 \\
H R=V_{0} / V_{T}
\end{gathered}
$$

\section{Mucoadhesion test}

The mucoadhesion properties of coated microspheres were studied to examine the adhesiveness of the microspheres to the mucosa at the site of absorption/application, following institutional animal ethical committee guidelines and were performed by the following tests:

\section{Ex vivo mucoadhesive strength determination}

The coated microsphere suspension was prepared in simulated intestinal fluid $T S$, and the number of microsphere per $\mathrm{mL}\left(N_{o}\right)$ was determined by optical microscopy. One $\mathrm{mL}$ of the above suspension was fed to overnight-fasted Albino rats of either sex (in a group of four) using an oral feeding needle. The rats were sacrificed at an interval of $0,4,8$, and 12 hours to isolate their stomach and intestinal region. The stomach and intestines were then cut open longitudinally to count the number of microspheres adhering to these regions $\left(N_{S}\right)$. Percent adhesive strength test result of all formulation batches was reported in percent adhesive strength and was calculated using equation- $8 .{ }^{17}$

$$
\text { Percent adhesive strength }=\left[N_{S} N_{0}\right] \times 100
$$

\section{In vitro wash-off test}

Freshly excised pieces of intestinal mucosa $(2 \mathrm{~cm} \times 2 \mathrm{~cm})$ from sheep were mounted onto a glass slide $(8 \mathrm{~cm} \times 3 \mathrm{~cm})$ with cyanoacrylate glue. Coated microspheres ( 100 numbers) were accurately counted and were spread onto wet rinsed intestinal mucosa tissue followed by hanging it onto one of the groves of a USP tablet disintegration test apparatus (DT 1000; Labindia Instruments Pvt Ltd, Mumbai, India), with continuous oxygen supply. The apparatus was operated giving tissue specimen regular up-and-down movements within the beaker of disintegration test apparatus, containing 
simulated intestinal fluid $T S$ at $37 \pm 1^{\circ} \mathrm{C} .{ }^{25}$ The number of microspheres still adhering onto the tissue was counted at hourly intervals up to 12 hours.

\section{In vitro release study}

The in vitro release profile of $B$. coagulans from coated microspheres was studied using a USP basket apparatus (TDT-06T; Electrolab, Mumbai, India) at $37 \pm 0.5^{\circ} \mathrm{C}$ and $100 \mathrm{rpm}$ containing $900 \mathrm{~mL}$ of sterile dissolution medium, namely, the simulated gastric fluid $T S$ and the simulated intestinal fluid TS. About $500 \mathrm{mg}$ of accurately weighed coated microspheres was placed in a basket (wrapped with 100 mesh nylon cloth) of the dissolution apparatus. Five $\mathrm{mL}$ of dissolution medium was withdrawn at a predetermined time interval up to 18 hours followed by immediate replacement with an equal volume of fresh dissolution medium. After suitable dilution samples were subjected for viable spore count, the result was presented as percent viable B. coagulans cells released.

In vitro release kinetic studies, statistical evaluation, and data fitting

The kinetic model describes drug dissolution from the solid dosage form, where the dissolved amount of the drug as a function of test time was studied. Under appropriate test conditions, a dissolution profile can characterize the product more precisely than a single point dissolution test. A mean value of three determinations at each time point was used to fit an in vitro drug dissolution profile of all formulation batches to different kinetic models so as to find the best fitting kinetic model and to determine their release exponents, while the mean value of twelve determinations was used to estimate the factors of the model-independent approach. ${ }^{26,27}$ In vitro release kinetic studies, statistical evaluation, data fitting, nonlinear least square curve fitting, simulation, and plotting were performed using Excel software (v 2007; Microsoft Software Inc, Redmond, WA) so as to determine the parameters of each equation.

\section{ANOVA-based procedures}

Statistical analysis of in vitro release data and other data were performed using one way ANOVA at a significance level of $5 \%(P<0.05)$ using Excel.

\section{Model-independent methods (pair-wise procedures)}

A comparison of the dissolution profile between products helps to assure similarity in product performance and shows bioequivalence. The model-independent mathematical approach is employed to compare the dissolution profile using three factors: $f_{1}$, equation-9; $f_{2}$, equation-10; and Rescigno index $\left(\xi_{i}\right)$, equation-11. According to the nature of measurement, $f_{1}$ was described as the difference factor and $f_{2}$ as the similarity factor and are determined by employing cumulative data. The factor $f_{1}$ is proportional to the average difference between the two profiles and indicates the percent error between two curves over all time points, whereas factor $f_{2}$ is inversely proportional to the average squared difference between two profiles and is a logarithmic transformation of the sum-squared error of difference between the test $T_{t}$ and reference products $R_{t}$. Rescigno index $\left(\xi_{1}\right.$ and $\left.\xi_{2}\right)$, a dimensional index, refer to area differences for noncumulative data and refer to the difference between the dissolved amount of the test and reference product in a given time interval.

$$
f_{1}=\left\{\left[\sum_{\mathrm{t}=1}^{\mathrm{n}}\left|R_{t}-T_{t}\right|\right] /\left[\sum_{\mathrm{t}=1}^{\mathrm{n}} R_{t}\right]\right\} \times 100
$$

$$
\begin{gathered}
f_{2}=50 \times \log \left\{\left[1+(1 / \mathrm{n}) \sum_{\mathrm{t}=1}^{\mathrm{n}}\left(R_{t}-T_{t}\right)^{2}\right]^{-0.5}\right\} \times 100 \\
\xi_{i}=\left[\left\{\sum_{\mathrm{t}=1}^{\mathrm{n}}\left|d_{T}(t)-d_{R}(t)\right|\right\} /\left\{\sum_{\mathrm{t}=1}^{\mathrm{n}}\left|d_{T}(t)-d_{R}(t)\right|^{i}\right\}\right]^{1 / i}
\end{gathered}
$$

Note that $R_{t}$ is the cumulative percentage dissolved from the reference product; $T_{t}$ is from the test product at each of the selected time points, $\mathrm{n}$, of the test and the product; $d_{T}(t)$ is the test product dissolved amount; $d_{R}(t)$ is the reference product dissolved amount at each time point; and $i$ is any positive integer number.

\section{Model-dependent methods}

Model-dependent mathematical approaches including zero order, first order, Hixson-Crowell and Weibull model, as listed in Table 2, were applied considering the amount of viable cell release as a function of test time. The following plots were then plotted: cumulative percent viable cell release vs time (zero order kinetic model), log cumulative percent viable cell release vs time (first order kinetic model), cube root of percent drug remaining in matrix vs time (Hixson-Crowell cube root), and logarithm of the dissolved amount of drug vs the logarithm of time (Weibull model). Higuchi model was not considered as the prepared microspheres fail to comply to the assumptions of this model. 
Table 2 Mathematical models used to describe dissolution curves

\begin{tabular}{ll}
\hline Zero order & $\mathrm{Q}_{1}=\mathrm{Q}_{0}+\mathrm{K}_{0} \mathrm{t}$ \\
First order & $\ln W_{1}=\ln \mathrm{W}_{0}+K t$ \\
Hixson-Crowell & $Q_{0}{ }^{1 / 3}-Q_{1}^{1 / 3}=K_{s} t$ \\
Weibull & $\log [-\ln (I-m)]=b \log \left(t-T_{i}\right)-\log \alpha$ \\
\hline
\end{tabular}

Notes: Where $Q_{0}$ is the initial amount of drug in the pharmaceutical dosage form, $Q_{1}$ is the amount of drug in the pharmaceutical dosage form at time $t, W_{0}$ is initial amount of drug in the dosage form, $W_{1}$ is the amount of drug released in time $t$, and $K_{0}$ is the zero order proportionality constant, and $K$ is the first order release rate constant, $K$ is a constant incorporating the surface-volume relation, $m$ is the accumulated fraction of the drug in solution at time $t, \alpha$ is the time scale of the process, $T_{i}$ is the location parameter represents the lag time before the onset of the dissolution or release process, and $b$ is the shape parameter.

\section{In vivo probiotic activity evaluation}

An in vivo probiotic activity evaluation of coated microspheres was performed using the mouse model Enterococci stool colonization method described by Donskey et al following institutional animal ethical committee guidelines. One $\mathrm{mL}$ of coated microspheres dispersion $\left(10^{2} \mathrm{cfu} / \mathrm{mL}\right)$, in simulated intestinal fluid $T S$, was orally fed to mice (in a group of six) using an oral feeding needle. The stools were collected periodically at six hour intervals up to 48 hours and subjected for enterococci colonization density study. ${ }^{9}$

\section{Accelerated stability study of microspheres}

Following ICH guidelines, formulation batches of microspheres were stored at several conditions of temperature and humidity $\left(30 \pm 2{ }^{\circ} \mathrm{C} / 65 \pm 5 \% \mathrm{RH}\right.$ and $40 \pm 2{ }^{\circ} \mathrm{C} / 75 \pm 5 \%$ $\mathrm{RH}$ ) in a stability analysis chamber (Darwin Chambers Company, St Louis, MO) and in a refrigerator $\left(2-8^{\circ} \mathrm{C}\right)$ for a period of 12 weeks. ${ }^{28}$ The samples were subjected for viable $B$. coagulans cell content, color, and texture analysis at 2-week intervals. These results were compared with those of the initial results (results of analysis of samples prior to stability charging) and control samples kept at $2-8^{\circ} \mathrm{C}$. The absence of any statistically significant decrease in viable $B$. coagulans cell content indicates product stability with the excipient and at the storage condition.

\section{Results and discussion}

The coacervation and phase separation technique described here appears to be a suitable method for the preparation of enteric-coated hypromellose microspheres loaded with $B$. coagulans. It is a two-step process, simple and less time consuming, and eliminates the exposure of B. coagulans to high temperatures, organic solvents, and mechanical stress, thereby maintaining their viability during processing. Temperatures above $20^{\circ} \mathrm{C}$ and nonaqueous solvents adversely affect and decrease the viability of $B$. coagulans, thus the developmental processes of enteric-coated microsphere was carried out below $20^{\circ} \mathrm{C}$ in aqueous medium. Hypromellose is soluble in cold water and its solubility in water decreases with increase in temperature and is insoluble in organic solvents such as chloroform, dichloromethane, ether, and acetone. ${ }^{20}$ Hypromellose phthalate is soluble in aqueous alkali and is insoluble in water and propan-2-ol. ${ }^{20}$ Hypromellose as a mucoadhesive polymer and hypromellose phthalate as a coating polymer were selected due to their abovementioned properties. Tween- 80 was incorporated in the formulation as a dispersing agent for homogenously dispersing $B$. coagulans cells and PEG-200 was incorporated in the coating solution formulation as a plasticizer to impart plasticity to the coat and to prevent it from splitting and cracking.

The percent yield value of the formulation batches lie within the range $54.6 \%-68.1 \% \mathrm{w} / \mathrm{w}$ while entrapment efficiency value lies within the range $67.68 \%-85.36 \% \mathrm{w} / \mathrm{w}$, and both were found to vary with differences in the grade of hypromellose and the $B$. coagulans-to-hypromellose ratio (Table 1). The highest percent yield value was observed with the formulation containing Methocel E5 Premium LV. The effect of the grade of hypromellose on percent yield value is the following order: Methocel E5 Premium LV > Methocel E15 Premium LV > Methocel K15M Premium. A similar trend was also found in the case of the entrapment efficiency value and the highest value was also observed with formulations containing Methocel E5 Premium LV. It was also observed that the percent yield and entrapment efficiency values increase with a decrease in B. coagulansto-hypromellose ratio (Table 1).

The percent swelling value varies with differences in the grade of HPMC, and the maximum percent swelling value was observed with Methocel E5 Premium LV. The effect of the grade of hypromellose on the percent swelling value follows the order of Methocel E5 Premium LV > Methocel E15 Premium LV > Methocel K15M Premium while the B. coagulans-to-HPMC ratio does not have a statistically significant effect on the percent swelling value. The percent swelling value of all formulation batches lies between 0.85 and 1.36 (Table 3 ).

Prepared B. coagulans loaded mucoadhesive microspheres were spherical in shape with a smooth surface and had no holes/ruptures on the surface. A scanning electron microscopy photograph of formulation-F1 which enumerates microsphere particle size and morphology is shown in Figure 1.

The mean particle size value of all formulation batches lies between $26.61 \mu \mathrm{m}$ and $49.01 \mu \mathrm{m}$ (Table 3). Variation in the mean particle size was observed with differences in 
Table 3 Percent swelling, mean particle size, zeta potential, and percent adhesive strength values of microspheres of all formulation batches

\begin{tabular}{lllll}
\hline Formulation code & Percent swelling & $\begin{array}{l}\text { Mean particle } \\
\text { size }(\mu \mathrm{m})\end{array}$ & $\begin{array}{l}\text { Zeta potential }(\mathrm{mV}) \text { of } \\
\text { uncoated microspheres }\end{array}$ & $\begin{array}{l}\text { Percent adhesive } \\
\text { strength }\end{array}$ \\
\hline FI & $1.23 \pm 0.61$ & $26.614 \pm 1.15$ & $-15.86 \pm 0.45$ & $83.1 \pm 1.23$ \\
F2 & $1.28 \pm 0.56$ & $27.036 \pm 1.34$ & $-15.61 \pm 0.92$ & $83.4 \pm 1.35$ \\
F3 & $1.36 \pm 0.59$ & $27.134 \pm 1.64$ & $-16.01 \pm 0.81$ & $82.8 \pm 1.37$ \\
F4 & $1.10 \pm 0.50$ & $33.453 \pm 1.58$ & $-16.17 \pm 0.65$ & $78.1 \pm 1.17$ \\
F5 & $1.14 \pm 0.54$ & $34.248 \pm 1.71$ & $-16.06 \pm 0.83$ & $78.9 \pm 1.24$ \\
F6 & $1.19 \pm 0.59$ & $33.264 \pm 1.39$ & $-15.97 \pm 0.67$ & $78.5 \pm 1.41$ \\
F7 & $0.85 \pm 0.34$ & $48.409 \pm 2.32$ & $-13.67 \pm 0.87$ & $72.6 \pm 1.36$ \\
F8 & $0.87 \pm 0.46$ & $48.952 \pm 2.24$ & $-13.45 \pm 0.53$ & $73.8 \pm 1.16$ \\
F9 & $0.89 \pm 0.41$ & $49.013 \pm 2.19$ & $-13.28 \pm 0.41$ & $72.3 \pm 1.14$ \\
\hline
\end{tabular}

Note: Data are presented as mean value $\pm S E, n=3$.

the grade of hypromellose. The highest mean particle size value was observed with formulations containing Methocel K15M Premium. The effect of the grade of hypromellose on the mean particle size value follows the order of Methocel K15M Premium > Methocel E15 Premium LV > Methocel E5 Premium LV (Figure 2 and Table 3). Variation in B. coagulans-to-hypromellose ratio does not influence the mean particle size value of formulation batches. The zeta potential value (Table 3 ) of core microspheres was negative as expected due to the methoxy group of hypromellose. Core microspheres prepared with the Methocel E15 Premium LV and the Methocel E5 Premium LV possessed nearly the same zeta potential value as both have the same ratio of methoxy and hydroxypropoxy groups, and are both higher than that prepared with Methocel K15M Premium. This may be due to an increase in the methoxy content of hypromellose polymer. A nearly constant negative zeta potential value $(-7.66 \pm 0.87)$ was observed with coated microspheres of all formulation batches, which is lower than that of uncoated microspheres, confirms the presence of hypromellose phthalate on the surface of microspheres. The zeta potential report of uncoated

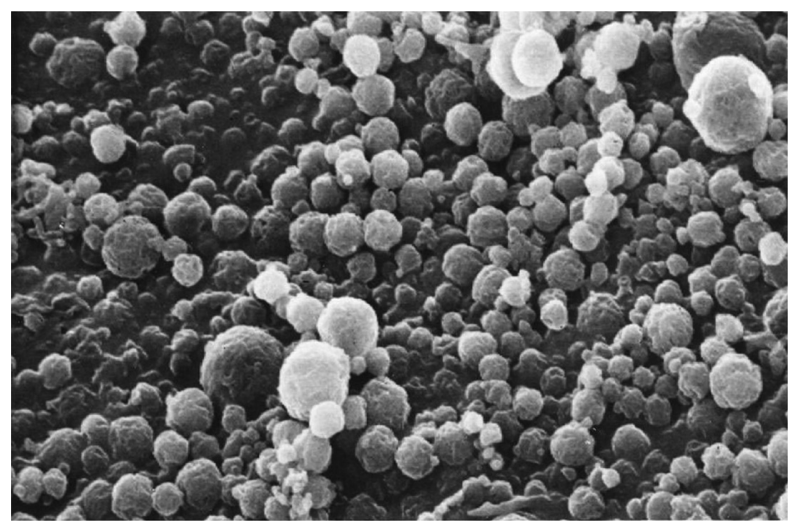

Figure I Scanning electron microscopy of microspheres of formulation batch FI. microspheres from formulation-F1 is presented in Figure 3. The flow properties of formulation batches lie between the passable and very poor range.

The percent adhesive strength value of all formulation batches, as a measure of ex vivo mucoadhesive strength test, lies between $72.3 \%$ and $83.1 \%$, and an increase in B. coagulans-to-hypromellose ratio does not affect it (Table 3). The highest percent adhesive strength value was observed with Methocel E5 Premium LV and the effect of the grade of hypromellose on percent adhesive strength value follows the order of Methocel E5 Premium LV > Methocel E15 Premium LV > Methocel K15M Premium. The in vitro wash-off test results (Table 4), as a measure of mucoadhesive efficiency, reveals that even after 12 hours, some of the microspheres remained adhered to the intestinal mucosa indicating that microspheres possess strong mucoadhesion affinity for the intestinal mucosa. The above experimental results suggest that mucoadhesion properties of microspheres vary with differences in the grade of polymer and does not vary with differences in the $B$. coagulans-to-hypromellose ratio. Microspheres possessing strong mucoadhesion affinity

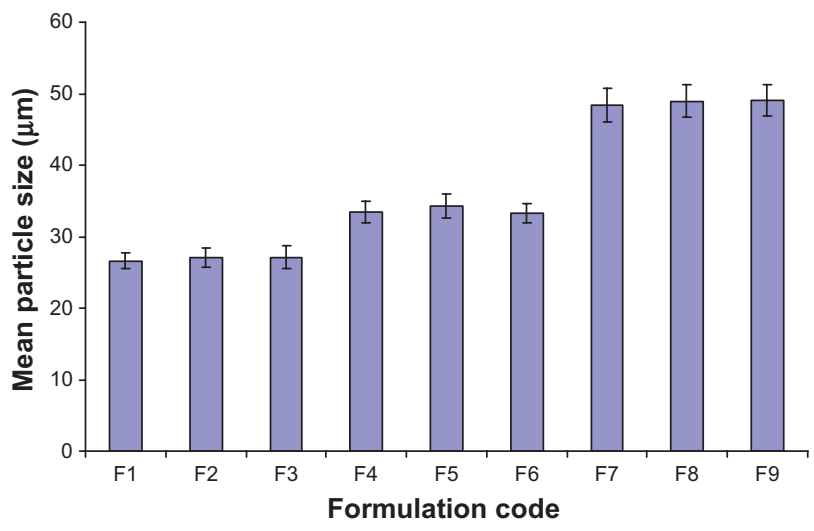

Figure 2 Histogram of mean particle size distribution of all formulation batches. 


\section{Results}

Zeta potential $(\mathrm{mV}):-15.8$

Zeta deviation $(\mathrm{mV}): 9.36$

Conductivity (ms/cm): 0.0885
Mean (mV)

Peak 1: $\quad-15.8$

Peak 2: 13.8

Peak 3: 0.00
Area (\%)

99.7

0.3

0.0
Width (mV)

9.20

0.00

0.00

Zeta potential distribution

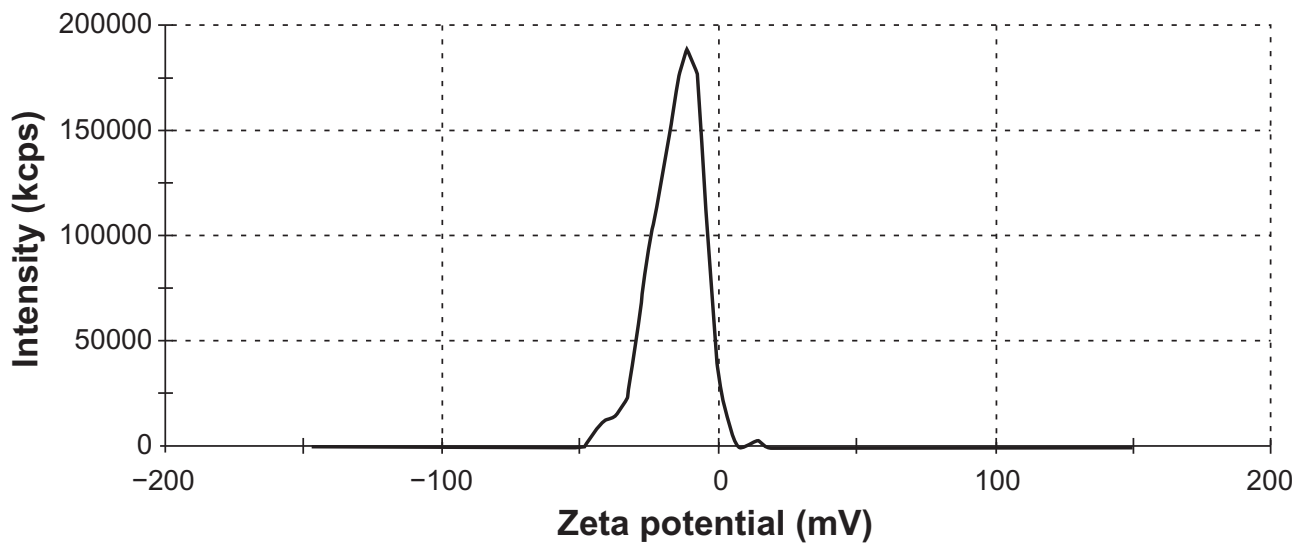

Figure 3 Zeta potential report of uncoated microspheres from formulation batch FI.

for intestinal mucosa may thus be retained in the intestinal tract for an extended period of time.

In simulated gastric fluid $T S$, the amount of B. coagulans released from the coated microsphere system is negligible, while in simulated intestinal fluid $T S, B$. coagulans release is almost regulated and extended within the investigational period of 18 hours (Figure 4). This indicates that entericcoating of microspheres has been competently protecting the viability of $B$. coagulans in gastric $\mathrm{pH}$, preventing the release of $B$. coagulans in gastric $\mathrm{pH}$, and releasing $B$. coagulans in the intestinal $\mathrm{pH}$.

The model independent (pair wise approach) release exponents $\left(f_{1}, f_{2}, \xi_{1}\right.$ and $\left.\xi_{2}\right)$ values are listed in Table 5 . Normally, regulatory authorities have set a public standard of $f_{1}$ values between 1 and 15 , and $f_{2}$ values between 50 and
100 to indicate similarity between two dissolution profiles, while the $\xi_{1}$ and $\xi_{2}$ indices always present values between 0 and 1 inclusive, where an index value of 0 denotes two identical release profiles, and a value of 1 denotes when the drug from either the test or the reference is not released at all. ${ }^{26,27}$ Data from Table 5 reveal that, for all formulation pairs, the $\xi_{1}$ values lie between 0.06 and 0.24 , and $\xi_{2}$ values lies between 0.14 and 0.32 (ie, above 0 and below 1), and the $f_{1}$ value lies between 16.85 and 42.60 (ie, above 15), and for almost all formulation pairs, the $f_{2}$ value lies between 27.54 and 50.00 (ie, below 50) indicating dissimilarity in product performance of the formulation batches when compared to each other, ie, intrapolymer (having the same grade of hypromellose but differing from each other by $B$. coagulansto-hypromellose ratio) and interpolymer (having the same

Table 4 Results of in vitro wash-off test of all formulation batches

\begin{tabular}{|c|c|c|c|c|c|c|c|}
\hline \multirow{2}{*}{$\begin{array}{l}\text { Formulation } \\
\text { code }\end{array}$} & \multicolumn{7}{|c|}{ Percent microspheres adhering to tissue at time points (in hours) } \\
\hline & $\mathbf{I h}$ & $2 \mathrm{~h}$ & $4 \mathrm{~h}$ & $6 \mathrm{~h}$ & $8 \mathrm{~h}$ & $10 \mathrm{~h}$ & $12 \mathrm{~h}$ \\
\hline $\mathrm{FI}$ & $62 \pm 1.6$ & $49 \pm 2.0$ & $34 \pm 2.1$ & $22 \pm 1.9$ & $16 \pm 1.5$ & $13 \pm 1.2$ & $09 \pm 1.1$ \\
\hline $\mathrm{F} 2$ & $63 \pm 1.2$ & $45 \pm 1.0$ & $36 \pm 1.4$ & $24 \pm 1.8$ & $18 \pm 1.7$ & $12 \pm 1.1$ & $08 \pm 0.8$ \\
\hline F3 & $69 \pm 2.2$ & $48 \pm 1.1$ & $32 \pm 1.8$ & $21 \pm 1.6$ & $15 \pm 1.3$ & $10 \pm 1.5$ & $07 \pm 1.1$ \\
\hline $\mathrm{F} 4$ & $71 \pm 2.1$ & $58 \pm 1.2$ & $41 \pm 1.6$ & $33 \pm 1.7$ & $22 \pm 2.0$ & $15 \pm 1.9$ & $09 \pm 1.0$ \\
\hline F5 & $72 \pm 1.9$ & $57 \pm 2.3$ & $39 \pm 2.0$ & $32 \pm 1.5$ & $24 \pm 1.8$ & $16 \pm 1.8$ & $11 \pm 1.8$ \\
\hline F6 & $73 \pm 2.0$ & $60 \pm 1.8$ & $43 \pm 2.2$ & $35 \pm 1.9$ & $26 \pm 2.0$ & $18 \pm 1.9$ & $12 \pm 1.7$ \\
\hline F7 & $89 \pm 2.1$ & $79 \pm 2.1$ & $62 \pm 2.0$ & $40 \pm 1.5$ & $32 \pm 2.1$ & $26 \pm 2.0$ & $16 \pm 1.9$ \\
\hline F8 & $86 \pm 1.8$ & $76 \pm 2.4$ & $61 \pm 2.1$ & $39 \pm 1.9$ & $29 \pm 1.9$ & $18 \pm 2.2$ & $13 \pm 1.5$ \\
\hline F9 & $85 \pm 1.5$ & $74 \pm 2.0$ & $58 \pm 2.3$ & $43 \pm 2.1$ & $30 \pm 1.9$ & $21 \pm 1.7$ & $12 \pm 2.0$ \\
\hline
\end{tabular}

Note: Data are presented as mean value $\pm S E, n=3$. 


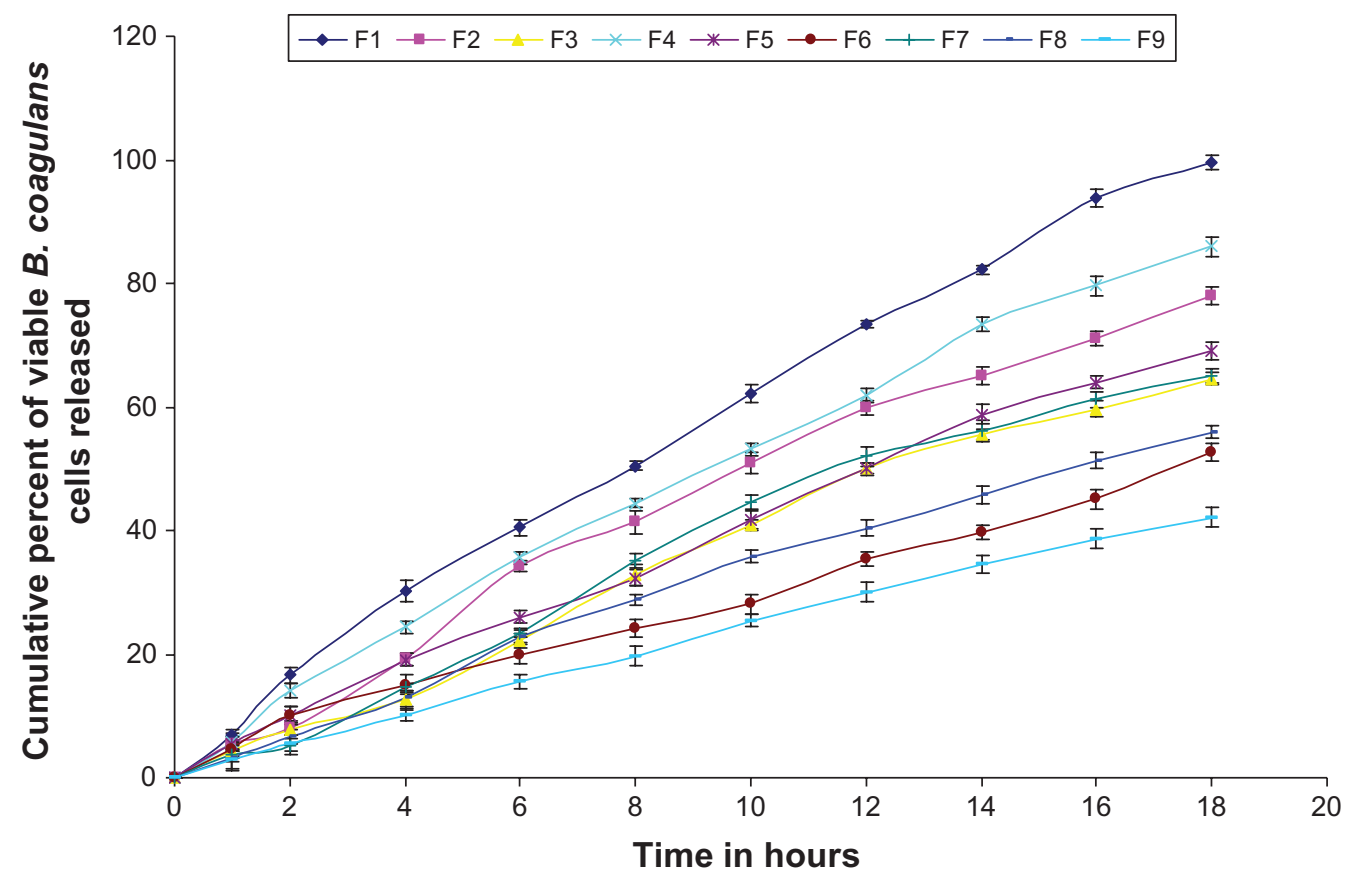

Figure 4 Comparative dissolution profile (model dependent, Zero-order kinetic model) of all formulation batches.

ratio of B. coagulans-to-hypromellose but differs from each other by grade of hypromellose).

The values for the kinetic constant and release exponent of model-dependent approaches (zero-order, Weibull) are listed in Table 6. The mechanism of B. coagulans release from the microspheres follows the zero-order kinetic model, since the plot of cumulative percent viable cell release versus time were found to be linear, and have a highest regression

Table 5 Mean value of dissimilarity factor $\left(f_{1}\right)$, similarity factor $\left(f_{2}\right)$, and two indices of rescigno $\left(\xi_{1}\right.$ and $\left.\xi_{2}\right)$

\begin{tabular}{lllll}
\hline Formulation pair & $f_{1}$ & $f_{2}$ & $\xi_{1}$ & $\xi_{2}$ \\
\hline FI vs F2 & 24.000 & 40.000 & 0.1212 & 0.1691 \\
FI vs F3 & 42.397 & 27.543 & 0.2128 & 0.3154 \\
F2 vs F3 & 24.000 & 45.000 & $0.094 I$ & 0.2264 \\
F4 vs F5 & 21.279 & 47.073 & $0.109 I$ & 0.1422 \\
F4 vs F6 & 42.604 & 31.385 & $0.240 I$ & 0.3033 \\
F5 vs F6 & 27.089 & 45.404 & 0.1345 & 0.2362 \\
F7 vs F8 & 16.854 & 56.251 & 0.0752 & 0.2012 \\
F7 vs F9 & 38.000 & 39.000 & 0.2147 & 0.3027 \\
F8 vs F9 & 25.924 & 51.836 & 0.1418 & 0.1818 \\
FI vs F4 & 21.316 & 41.613 & 0.0729 & 0.2126 \\
FI vs F7 & 40.594 & 28.665 & 0.2091 & 0.2742 \\
F4 vs F7 & 24.500 & 44.421 & 0.1383 & 0.2290 \\
F2 vs F5 & 19.419 & 47.993 & 0.0607 & 0.2614 \\
F2 vs F8 & 34.406 & 36.711 & 0.1643 & 0.2751 \\
F5 vs F8 & 19.476 & 53.487 & 0.1046 & 0.1861 \\
F3 vs F6 & 24.409 & 49.132 & 0.1014 & 0.2626 \\
F3 vs F9 & 35.860 & 41.129 & 0.2110 & 0.2733 \\
F6 vs F9 & 18.000 & 63.000 & 0.1120 & 0.2117 \\
\hline
\end{tabular}

coefficient $\left(r^{2}\right)$ value in comparison to that of the first order, Hixson-Crowell, and Weibull model when compared with intraformulation batches. For all formulation batches, the zero-order kinetic model $r^{2}$ value lies between 0.9820 and 0.9978 , while the zero-order kinetic constant value lies between 2.3708 and 5.5517. In Weibull model, the shape parameter characterizes the curve as either exponential ( $\beta=1$, case-1), sigmoid or S-shaped with upward curvature followed by a turning point ( $\beta>1$, case-2), or parabolic with a higher initial slope, and after that consistent with the exponential ( $\beta<1$, case-3), while the location parameter $\left(T_{d}\right)$ characterizes the time interval necessary to dissolve or release $63.2 \%$ of the drug present in the pharmaceutical dosage form, determined by employing relation $\alpha=\left(T_{d}\right)^{\beta}$ from the shape parameter $(\beta)$ and scale parameter $(\alpha){ }^{27}$ Study of shape parameter values of the Weibull model from Table 6 reveal that the curve is sigmoid or S-shaped with upward curvature followed by a turning point $(\beta>1)$, while the $T_{d}$ value of all formulation batches lies between 9.31 and 30.06 .

A plot showing the viable $B$. coagulans release profile following the zero-order kinetic model of all formulation batches is shown in Figure 4, and reveals that an increase in the $B$. coagulans-to-polymer ratio significantly decreases the rate of viable $B$. coagulans release from microspheres while variation in the grade of hypromellose influences the rate of viable $B$. coagulans release from microspheres following 
Table 6 Linearization of B. coagulans dissolution profile using model-dependent approach, ie, the Zero-order and the Weibull

\begin{tabular}{|c|c|c|c|c|c|c|}
\hline \multirow[t]{2}{*}{ Formulation code } & \multicolumn{2}{|c|}{$\begin{array}{l}\text { Zero-order kinetic } \\
\text { constants }\end{array}$} & \multicolumn{4}{|c|}{ Kinetic constant and release exponents of Weibull model } \\
\hline & $K_{0}$ & $r^{2}$ & $r^{2}$ & $\alpha$ & $\beta$ & $T_{d}$ \\
\hline $\mathrm{FI}$ & 5.5517 & 0.9927 & $0.92035 \pm 0.354$ & $72.342 \pm 0.5296$ & $1.2891 \pm 0.1341$ & $27.695 \pm 0.1242$ \\
\hline F2 & 4.4534 & 0.9851 & $0.91701 \pm 0.362$ & $54.309 \pm 0.4556$ & $1.1738 \pm 0.1249$ & $30.059 \pm 0.1148$ \\
\hline F3 & 3.7874 & 0.9892 & $0.95962 \pm 0.252$ & $40.209 \pm 0.3018$ & $1.2334 \pm 0.0895$ & $19.984 \pm 0.0865$ \\
\hline F4 & 4.8132 & 0.9928 & $0.95497 \pm 0.266$ & $55.978 \pm 0.3798$ & $1.3332 \pm 0.1024$ & $20.474 \pm 0.1123$ \\
\hline F5 & 3.8893 & 0.9958 & $0.97165 \pm 0.211$ & $43.510 \pm 0.2892$ & $1.3789 \pm 0.0833$ & $15.429 \pm 0.0713$ \\
\hline F6 & 2.7205 & 0.9928 & $0.98056 \pm 0.175$ & $31.717 \pm 0.2459$ & $|.5497 \pm 0.077|$ & $9.3063 \pm 0.0701$ \\
\hline F7 & 3.8970 & 0.9820 & $0.92602 \pm 0.34 I$ & $42.004 \pm 0.3736$ & $1.1026 \pm 0.1102$ & $29.664 \pm 0.1001$ \\
\hline F8 & 3.1816 & 0.9920 & $0.94696 \pm 0.289$ & $35.391 \pm 0.3250$ & $1.1972 \pm 0.1002$ & $19.670 \pm 0.1102$ \\
\hline F9 & 2.3708 & 0.9978 & $0.96981 \pm 0.218$ & $25.926 \pm 0.2424$ & $1.3108 \pm 0.0818$ & $11.980 \pm 0.1018$ \\
\hline
\end{tabular}

Notes: Where $K_{0}$ is the zero order rate constant, $r^{2}$ is the regression coefficient, $\alpha$ is the scale parameter (time scale of the process), $\beta$ is the shape parameter, and $T_{d}$ is the location parameter. Data are presented as mean value $\pm S E, n=3$.

the order of Methocel E5 Premium LV > Methocel E15 Premium LV > Methocel K15M Premium.

In vivo probiotic activity evaluation showed that oral administration of coated microspheres of B. coagulans from all formulation batches resulted in statistically significant reductions in the density of enterococci colonization in the stool of Albino mice from 24 hours to 36 hours. Satisfactory in vivo probiotic activity in the mouse model showed that the prepared B. coagulans loaded microspheres have potential for follow-up studies to verify its potentiality for human use.

The stability results reveal that prepared B. coagulans loaded microspheres exhibit adequate stability at the storage condition of $30 \pm 2{ }^{\circ} \mathrm{C} / 65 \pm 5 \% \mathrm{RH}$, as no statistically significant decreases in viable $B$. coagulans cell content were observed, and also signifies that the $B$. coagulans cells are compatible with the excipients used in the development of microspheres. At the storage condition of $40 \pm 2{ }^{\circ} \mathrm{C} / 75 \pm 5 \%$ $\mathrm{RH}$, statistically significant decrease in viable $B$. coagulans cell content was observed, indicating product instability at this storage condition.

Formulation F1 (containing B. coagulans-to-Methocel E5 Premium LV with ratio of 1:1) was found to be superior to the other prototype formulations with respect to product performance, as it exhibited the highest entrapment efficiency, highest mucoadhesion efficiency, the ability to protect the viability of $B$. coagulans cells during storage and GI transit, and releases viable $B$. coagulans cells in the gut for an extended period of time, as shown via zero-order kinetics.

\section{Conclusion}

Experimental results suggest that enteric-coated hypromellose microspheres loaded with $B$. coagulans could be prepared by the conventional coacervation and phase separation method, and have the potential to deliver viable
B. coagulans cells into the gut for an extended period of time, while maintaining the viability of $B$. coagulans during storage and GI transit, and could be viewed as an alternative to conventional dosage forms. However, extensive in vivo studies are required to establish the use of mucoadhesive microspheres as an alternative to conventional dosage forms of B. coagulans.

\section{Acknowledgments}

The author wishes to thank Glenmark Pharmaceuticals Limited, Sinnar, Nasik, India, for the sample of freeze dried B. coagulans and hypromellose phthalate (HP-50). Words are insufficient to express my gratitude to Indoco Remedies Limited, Rabale, Mumbai, India, for samples of used grades of methocel. The author will remain indebted to Jadavpur University, Kolkata, India, for support to complete this work.

\section{Disclosure}

No conflicts of interest were declared in relation to this paper.

\section{References}

1. Mitsuoka T. Role of intestinal flora in health with special reference to dietary control of intestinal flora. In: Hga BH, Lee YK, editors. Microbiology applications in food biotechnology. London, UK: Elsevier Science Publishers Ltd; 1992:135-148.

2. Orrhage K, Nord CE. Bifidobacteria and lactobacilli in human health. Drugs Exp Clin Res. 2000;26(3):95-111.

3. Nakajima H, Suzuki Y, Kaizu H, Hirota T. Cholesterol lowering activity of ropy fermented milk. J Food Sci. 1992;57(6):1327-1329.

4. Singh J, Rivenson A, Tomita M, Shimamura S, Ishibashi N, Reddy BS. Bifidobacterium longum, a lactic acid-producing intestinal bacterium inhibits colon cancer and modulates the intermediate biomarkers of colon carcinogenesis. Carcinogenesis. 1997;18(4):833-841.

5. Kim HS, Gilliland SE. Lactobacillus acidophilus as a dietary adjunct for milk to aid lactose digestion in humans. J Dairy Sci. 1983;66(5): 959-966. 
6. Kirjavainen PV, Apostolou E, Salminen SJ, Isolauri E. New aspects of probiotics-a novel approach in the management of food allergy. Allergy. 1999;54(9):909-915.

7. Sanders ME, Morelli L, Tompkins TA. Sporeformers as human probiotics: Bacillus, Sporolactobacillus, and Brevibacillus. Compr Rev Food Sci Food Saf. 2003;2(3):101-110.

8. Krasaekoopt W, Bhandari B, Deeth H. Evaluation of encapsulation techniques of probiotics for yoghurt. Int Dairy J. 2003;13(1): 3-13.

9. Donskey CJ, Hoyen CK, Das SM, Farmer S, Dery M, Bonomo RA. Effect of oral Bacillus coagulans administration on the density of vancomycin-resistant enterococci in the stool of colonized mice. Lett Appl Microbiol. 2001;33(1):84-88.

10. Shah NP. Probiotic bacteria: selective enumeration and survival in dairy foods. J Dairy Sci. 2000;83(4):894-907.

11. Gilliand SE, Speck ML. Instability of Lactobacillus acidophilus in yogurt. J Dairy Sci. 1977;60(9):1394-1398.

12. Lankaputhra WEV, Shah NP. Survival of Lactobacillus acidophilus and Bifidobacterium spp in the presence of acid and bile salts. Cultured Dairy Products J. 1995;30(3):2-7.

13. O'Riordan K, Andrews D, Buckle K, Conway P. Evaluation of microencapsulation of a Bifidobacterium strain with starch as an approach to prolonging viability during storage. J Appl Microbiol. 2001;91(6):1059-1066.

14. Sultana K, Godward G, Reynolds N, Arumugaswamy R, Peiris P, Kailasapathy K. Encapsulation of probiotic bacteria with alginate-starch and evaluation of survival in simulated gastrointestinal conditions and in yoghurt. Int J Food Microbiol. 2000;62(1-2):47-55.

15. Chandramouli V, Kailasapathy K, Peiris P, Jones M. An improved method of microencapsulation and its evaluation to protect Lactobacillus spp. in simulated gastric conditions. J Microbiol Methods. 2004; 56(1):27-35.

16. Chowdary KPR, Rao YS. Mucoadhesive microspheres for controlled drug delivery. Biol Pharm Bul. 2004;27(11):1717-1724.
17. Belgamwar V, Shah V, Surana SJ. Formulation and evaluation of oral mucoadhesive multiparticulate system containing metoprolol tartarate: an in vitro-ex vivo characterization. Curr Drug Deliv. 2009;6(1): $113-121$.

18. Li CL, Martini LG, Ford JL, Roberts M. The use of hypromellose in oral drug delivery. J Pharm Pharmacol. 2005;57(5):533-546.

19. Bora PS, Puri V, Bansal AK. Physicochemical properties and excipient compatibility studies of probiotic Bacillus coagulans Spores. Sci Pharm. 2009;77(3):625-637.

20. Rowe RC, Sheskey PJ, Owen SC, editors. Handbook of pharmaceutical excipients. 5th ed. London, UK: Pharmaceutical Press; and Washington, DC: American Pharmacists Association; 2006:346-358.

21. United States Pharmacopoeial Convention (US). United States Pharmacopoeia-National Formulary (USP-NF) 2008. Rockville, MD: US Pharmacopoeial Convention, Inc; 2007:639-641, 814, 820.

22. Shakoori AR, Anwar S, Khurshed N, Riaz-ul-Haq. Biocidal activity of Bacillus species for Anopheles larvae. Folia Biol (Krakow). 1999; 47(3-4):143-148.

23. El-Gibaly I. Development and in vitro evaluation of novel floating chitosan microcapsules for oral use: comparison with non-floating chitosan microspheres. Int J Pharm. 2002;249(1-2):7-21.

24. Vyas TK, Babbar AK, Sharma RK, Singh S, Misra A. Intranasal mucoadhesive microemulsions of clonazepam: preliminary studies on brain targeting. J Pharm Sci. 2006;95(3):570-580.

25. Lehr CM, Bowstra JA, Tukker JJ, Junginer HE. Intestinal transit of bioadhesive microspheres in an in-situ loop in the rat. J Control Release. 1990;13(1):51-62.

26. Costa P, Sousa Lobo JM. Modeling and comparison of dissolution profiles. Eur J Pharm Sci. 2001;13(2):123-133.

27. Soni T, Choatai N. Assesment of dissolution profile of marketed aceclofenac formulations. J Young Pharma. 2010;2(1):21-26.

28. Dandagi PM, Mastiholimath VS, Gadad AP, Iliger SR. Mucoadhesive microspheres of propranolol hydrochloride for nasal delivery. Indian J Pharm Sci. 2007;69(3):402-407.
International Journal of Nanomedicine

\section{Publish your work in this journal}

The International Journal of Nanomedicine is an international, peerreviewed journal focusing on the application of nanotechnology in diagnostics, therapeutics, and drug delivery systems throughout the biomedical field. This journal is indexed on PubMed Central,

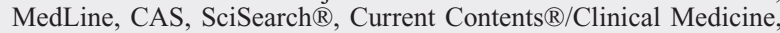

\section{Dovepress}

Journal Citation Reports/Science Edition, EMBase, Scopus and the Elsevier Bibliographic databases. The manuscript management system is completely online and includes a very quick and fair peer-review system, which is all easy to use. Visit http://www.dovepress.com/ testimonials.php to read real quotes from published authors. 